\title{
Optimization of location and size of distributed generations for maximizing their capacity and minimizing power loss of distribution system based on cuckoo search algorithm
}

\author{
Thuan Thanh Nguyen ${ }^{1}$, Trieu Ton Ngoc ${ }^{2}$, Thang Trung Nguyen ${ }^{3}$, Thanh-Phuc Nguyen ${ }^{4}$, Ngoc Au \\ Nguyen $^{5}$ \\ ${ }^{1,4}$ Faculty of Electrical Engineering Technology, Industrial University of Ho Chi Minh City, Ho Chi Minh City, Vietnam \\ ${ }^{2}$ Thu Duc College of Technology, Ho Chi Minh City, Vietnam \\ ${ }^{2,5}$ Faculty of Electrical and Electronics Engineering, Ho Chi Minh City University of Technology and Education, Ho Chi \\ Minh City, Vietnam \\ ${ }^{3}$ Power System Optimization Research Group, Faculty of Electrical and Electronics Engineering, Ton Duc Thang \\ University, Ho Chi Minh City, Vietnam
}

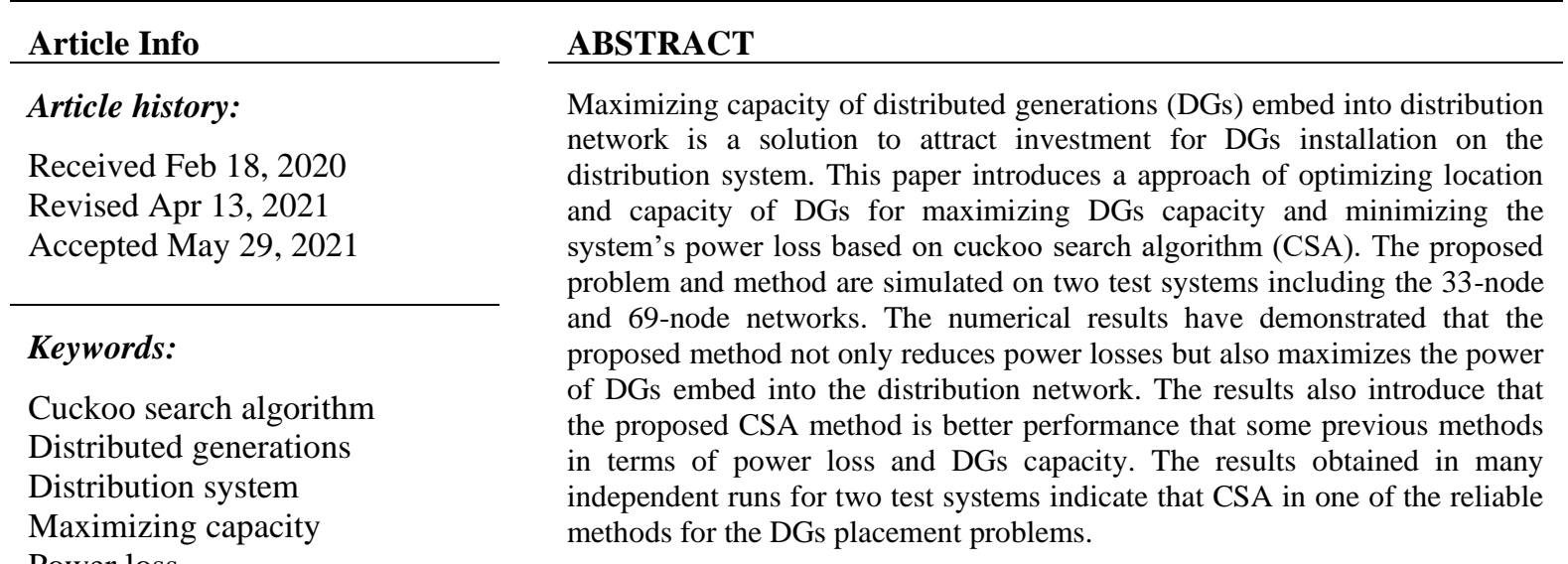

Power loss

\author{
Corresponding Author: \\ Thang Trung Nguyen \\ Power System Optimization Research Group \\ Faculty of Electrical and Electronics Engineering \\ Ton Duc Thang University \\ Ho Chi Minh City, Vietnam \\ Email: nguyentrungthang@tdtu.edu.vn
}

\section{INTRODUCTION}

Distributed generations (DGs) are power sources connected directly to distribution systems that have smaller capacity compared with the centralized power plants [1]. Installation of DGs in distribution system takes a lot of benefits related to technique, economy and environment [2]. In aspect of technical benefits, DGs placement not only help to increase the reliability and stability of the distribution system, quality of power supply and the available power capacity of the system but also decrease power loss, overload and oscillations of power system. In aspect of economic benefits, DGs placement help to reduce the investment costs for expanding the transmission, operation cost and reduce electricity bill for customer who installed small DGs such as photovoltaic or wind turbine. For the environmental benefits, DGs placement using renewable energy resources helps to reduce pollutant emissions which are caused by using the fossil energies 
for production of electricity. Due to the above benefits, the presence of DGs in distribution system has been raised rapidly [3]. Thus, the DGs placement problem to satisfy different goals is an important issue [4].

For searching the suitable location and capacity of DGs embedded to distribution system, there are two main groups of methods comprising of conventional mathematical techniques and modern mathematical techniques. The linear programming [5], mixed integer [6] and dynamic programming [7] are typical representatives in the first group while genetic algorithm [8], [9], particle swarm optimization [10], [11], honey bee mating optimization [12], adaptive cuckoo search (ACSA) [13], salp swarm algorithm (SSA) [14], stochastic fractal search (SFS) [15], coyote algorithm (COA) [16], combination of teaching learning based optimization and grey wolf optimizer (TLBO-GWO) [17], firefly algorithm [18], crow search algorithm [19] and whale optimization algorithm [20] are typical representatives for the second group. Compared to the first group, the second group of methods is stronger developed than the first one due to many advantages such as the better quality of obtained solution and the easier handle constraints. These advantages has been proven by using this group of methods for the DG problem as well as many other problems in the electrical system such as TCSC placement [21], wind, hydro and thermal scheduling [22] and reactive power planning [23]. In the near future, the methods that belong to the second group will continue to be developed and applied to the DGs placement problem in particular and the problems related to the power system in general.

In Vietnam as well as some countries in over the world, investors do not really want to invest for installation of DGs in the distribution system because costs for installation of DGs with small capacity connected to distribution system can be more expensive than that of power sources with large capacity located on the transmission system when compared in term of investment cost per unit of capacity. Therefore, one of the solutions to entice investment for DGs installation on the distribution system is maximizing the capacity of DGs that can embed to the distribution system. This paper demonstrates a DGs placement problem for maximizing DGs capacity connected into the distribution system and minimizing power loss based on CSA while satisfying the technical constraints consisting of current and voltage constraints and DGs capacity constraint. CSA is developed relied on the idea of breeding of cuckoo birds [24]. CSA generates new solutions using the Levy flight and selective random walk techniques. Until now CSA has been applied successfully to many engineering problems [25]. The effectiveness of CSA has been validated on two test distribution systems consisting of the 33-node and 69-node systems. The results are contrasted with those of the previous methods. Based on the numerical results, the main contributions of the paper are summarized is being as: (1) the DGs placement problem is considered in aspect of maximizing DGs capacity into distribution system and minimizing power loss of the distribution system, (2) the CSA is proposed for searching the optimal DGs location and capacity in the distribution system, (3) the performance of CSA is validated on two test systems including the 33-node and 69-node systems, (4) the proposed problem and solving method help to obtain more DGs capacity and power loss reduction contrasted with the previous methods.

\section{THE OBJECTIVE FUNCTION}

In order to attract the investment of DGs suppliers for placing DGs into the distribution network, one of the essential goals is to maximize their capacity that can be joined to the system because the higher DGs capacity is, the lower investment cost is. In addition, from the viewpoint of distribution system operation, one of the important technical factors that helps reduce operating costs is minimizing the power loss of the distribution network. Thus, the objective function of DGs placement problem to maximize DGs capacity and reduce losses is described as shown in (1):

$$
f_{1}=\max \left(\sum_{i=1}^{N_{D G}} P_{D G, i}\right)
$$

Where $P_{D G, i}$ is power of the ith DG; $N_{D G}$ is number of DGs that is integrated to distribution network.

$$
f_{2}=\min \left(\sum P_{\text {loss }}\right)
$$

Where $\sum P_{\text {loss }}$ is the total loss of distribution network.

The objective function of the DGs placement problem for maximum DGs capacity and minimum power loss is converted to the minimal optimization problem as shown in (3):

$$
\min o b j=\left(1-\frac{\sum_{i=1}^{N_{D G} P_{D G, i}}}{\sum P_{D G, \max }}\right)+\frac{\sum P_{\text {loss }}}{\sum P_{\text {loss }, 0}}
$$


Where $\sum P_{D G, \max }$ is the limit of total capacity of DGs; $\sum P_{\text {loss }, 0}$ is the total loss of the distribution network without DGs placement. DGs installation in the distribution network should satisfy the following constraints:

- Voltage and current limits: Placement of DGs will help to improve the voltage profile but it must not cause overvoltage and overcurrent.

$$
\left\{\begin{array}{l}
\mathrm{V}_{\min }^{\lim } \leq V_{i} \leq \mathrm{V}_{\text {max }}^{\text {lim }} ; i=1,2, \cdots, N_{b u} \\
L C F_{i} \leq L C F_{\text {max }}^{l i m} ; \quad i=1,2, \cdots, N_{b r}
\end{array}\right.
$$

Where $V_{\min }^{\text {lim }}$ and $V_{\max }^{\text {lim }}$ are the permitted minimum and maximum voltage which is set to 0.95 and 1.05 p.u; $L C F_{i}$ is load carrying factor of the ith line; $L C F_{\max }^{\lim }$ is the permit overload factor that is chosen to $1 ; N_{b u}$ and $N_{b r}$ are the number of buses and the number of lines in the distribution system.

- Power limits of DGs: In order to determine the maximum capacity of DGs that can be connected to the distribution system, the upper limit of each DG is not necessarily be concerned but the total capacity of DGs that is integrated to the distribution network need to consider. In this study, this value is assumed that it must be not exceed the sum of loads and the total power loss of the network:

$$
\sum_{i=1}^{N_{D G}} P_{D G, i} \leq \sum_{j=1}^{N_{b u}} P_{l o a d, j}+\sum P_{l o s s}
$$

Where $P_{l o a d, j}$ is the active load of the jth node of distribution system. In addition, the power balance constraint has to satisfy. Wherein, the total generating capacity of source and DG has to be equal to the sum of loads and loss power of the network [22], [23].

\section{THE CUCKOO SEARCH FOR MAXIMIZING DGs CAPACITY AND MINIMIZING POWER LOSS}

\subsection{The adaptive function for the DGs placement problem}

Each candidate solution produced by the optimization algorithm is evaluated the quality by the adaptive function. The better the solution is, the higher probability that the solution will survive and thrive in the population. The adaptive function for the DGs placement problem to maximize the DGs capacity and minimize the power loss is formulated as shown in (6):

$$
\min f=o b j+P \cdot\left[\left(\max \left(V_{\text {low }}-V_{\text {min }}^{\text {lim }}\right), 0\right)+\left(\max \left(V_{\text {max }}-V_{\text {max }}^{l i m}\right), 0\right)+\left(\max \left(L C F_{\max }-1\right), 0\right)\right]
$$

Where $o b j$ is the objective function determined by (3); $P$ is a penalty factor; $V_{\text {low }}$ and $V_{\text {max }}$ are the minimum and maximum voltage amplitudes of the network; $L C F_{\max }$ is the maximum current carrying factor of the network.

\subsection{Cuckoo search algorithm for searching DGs location and capacity}

In CSA, each cuckoo's egg is examined as a solution of the problem. For the DGs placement problem, there are two parts in a solution vector consisting location and capacity of DGs as shown in (7):

$$
\operatorname{sol}_{i}=\left[L_{j}, C_{j}\right] ; j=1, \ldots, N_{d g}
$$

Where $L_{j}$ and $C_{j}$ stand for location and capacity of the jth DG; $N_{d g}$ is number of DGs connected to distribution system. The variables which stand for the location of DGs will be rounded to integer number to indicate the location of DG. To start searching optimal solution of the DGs installation problem, the initial population is produced randomly below:

$$
\operatorname{sol}_{i, j}=\operatorname{sol}_{\min , j}+r_{1} \cdot\left(\operatorname{sol}_{\max , j}-\operatorname{sol}_{\min , j}\right)
$$

Where $\operatorname{sol}_{i, j}$ is the $\mathrm{jth}$ control variable of the ith solution $(\mathrm{i}=1, \ldots, \mathrm{N}$ and $\mathrm{j}=1, \ldots, \mathrm{D})$; $\mathrm{N}$ and $\mathrm{D}$ is population size and dimension of the problem; $r_{1}$ is a random number in [0,1]; $\operatorname{sol}_{\max , j}$ and $\operatorname{sol}_{\min , j}$ are the low and high bounds of the jth control variable.

To produce new solutions for searching the best solution of the problem, CSA uses two mechanisms consisting of the Lévy flight random walk and selective random walk techniques. In which, the former helps to explore the search space, the latter supports CSA to exploit the search space. The mathematical formulation of the Lévy flight random walk technique is expressed as shown in (9): 


$$
\operatorname{sol}_{i}=\operatorname{sol}_{i}+\theta \cdot\left(\operatorname{sol}_{i}-\operatorname{sol}_{\text {best }}\right) \cdot \operatorname{Levy}(\varphi)
$$

Where $\theta$ is the scale coefficient selected equal to $1 ; \varphi$ is distribution factor in $[0,2]$; sol $l_{\text {best }}$ is the best so far solution.

The mathematical formulation of selective random walk technique is expressed as shown in (10):

$$
\operatorname{sol}_{i}=\left\{\begin{array}{l}
\operatorname{sol}_{i}+r_{2} \cdot\left(\operatorname{sol}_{k}-\operatorname{sol}_{h}\right) ; \text { if } r_{3}<\gamma \\
\text { sol }_{i} ; \text { otherwise }
\end{array}\right.
$$

Where $r_{2}$ and $r_{3}$ are a random number in $[0,1] ; \gamma$ is the mutation factor selected to $0.2 ;$ sol $_{k}$ and $\operatorname{sol}_{h}$ are the solutions selected randomly in the population.

The whole steps of implementing CSA for the DGs placement problem are described in:

- $\quad$ Step 1: Initialize randomly the current population using (8).

- Step 2: Evaluate the adaptive function for the initial population by using (6) and specify the best solution.

- $\quad$ Step 3: Produce the new solutions based on the Lévy flight random walk technique using (9).

- $\quad$ Step 4: Evaluate the adaptive function for the new solutions by using (6) and renew the population by using the selection method to retain more good solutions and abandon bad solutions.

- Step 5: Update the best solution.

- Step 6: Produce the new solutions based on the selective random walk technique using (10).

- Step 7: Evaluate the adaptive function for the new solutions by using (6) and update the population by using the selection method to retain more good solutions and abandon bad solutions.

- $\quad$ Step 8: Update the best so far solution.

- $\quad$ Step 9: Repeat the step 3 for continuing to search the better solutions until the current iteration increases to the maximum value.

\section{NUMERICAL RESULTS}

For finding optimal location and capacity of DGs, the proposed CSA method is coded in MATLAB and run on a personal computer with CPU core-i5 $2.4 \mathrm{GHz}, \mathrm{RAM} 4 \mathrm{G}$. Two distribution systems consisting of the 33-node [26] and 69-node [27] presented in Figure 1 are used to optimize the location and size of DGs. Figure 1 (a) shows in 33-nodes test system and Figure 1 (b) shows in 69-nodes test system. For the first system, the rated current of branches is limited to $150 \mathrm{~A}$. For the second system, this value is assumed to 100 A. The number of DGs for both of the systems is three. For both of the test systems, the penalty coefficient for violation of constraints is set to 1000, the population size and the number of iterations are chosen to 30 and 300, respectively. In order to evaluate robustness of CSA, 50 independent runs have been executed for both of the systems.

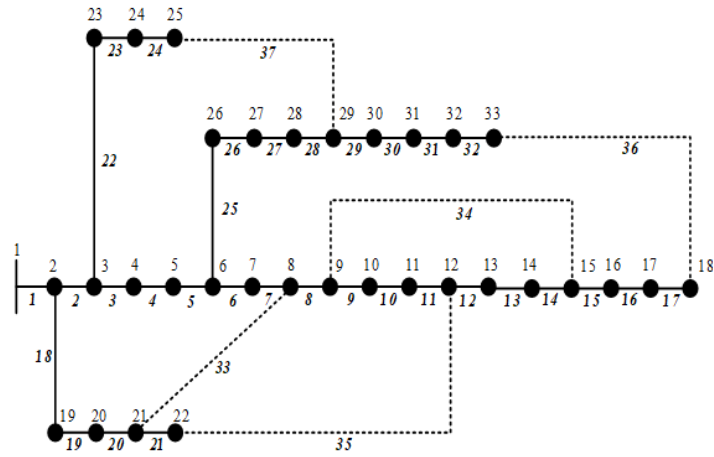

(a)

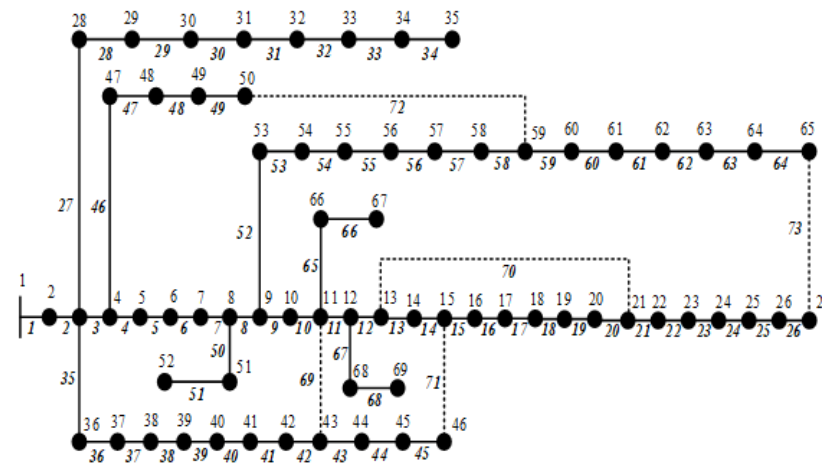

(b)

Figure 1. Two test distribution systems; (a) the 33-nodes test system, (b) the 69-nodes test system

\subsection{The obtained optimal solutions}

For the 33-node system, at the initial status the power loss in kilowatt is 202.6863, the minimum voltage amplitude and $\left(V_{\min }\right)$ the maximum load carrying factor $\left(L C F_{\max }\right)$ in per unit (p.u) are 0.9131 and 
1.4024. It can be seen that $V_{\min }$ and $L C F_{\max }$ of the initial system are violated the permit ranges. The optimal DGs location and capacity obtained by the proposed technique is presented in Table 1.

Table 1. Optimal DGs location and capacity for the 33-node network

\begin{tabular}{|c|c|c|c|c|c|c|}
\hline Term & None of DGs & DGs Placement & ACSA [13] & SFS [15] & SSA [14] & COA [16] \\
\hline DGs capacity in & & $1.9756(3)$ & $0.7798(14)$ & $0.7540 /(14)$ & $0.7536(33)$ & $1.0714(30)$ \\
\hline \multirow[t]{2}{*}{ MW (nodes) } & - & $0.7316(14)$ & $1.1251(24)$ & $1.0994 /(24)$ & $1.1004(23)$ & $0.7540(14)$ \\
\hline & & $1.0078(30)$ & $1.3496(30$ & $1.0714 /(30)$ & $1.0706(29)$ & $1.0994(24)$ \\
\hline Total DGs capacity & - & 3.7150 & 3.2545 & 2.9248 & 2.9246 & 2.9248 \\
\hline$\Delta P(\mathrm{~kW})$ & 202.6863 & 76.7556 & 74.26 & 71.47 & 71.45 & 71.4599 \\
\hline Loss reduction (\%) & - & $62.13 \%$ & $63.36 \%$ & $64.74 \%$ & $64.75 \%$ & $64.74 \%$ \\
\hline$V_{\min }(\mathrm{p} . \mathrm{u})$ & 0.9131 & 0.9696 & 0.9778 & 0.9687 & 0.9686 & 0.9687 \\
\hline$L C F_{\max }$ & 1.4024 & 0.7159 & - & - & - & - \\
\hline
\end{tabular}

After placement three DGs with capacity of 1.9756, 0.7316 and $1.0078 \mathrm{MW}$ at the 3rd, 14th and 30th nodes, the power loss is dropped from $202.6863 \mathrm{~kW}$ to $76.7556 \mathrm{~kW}$. The minimum voltage is improved from 0.9131 p.u to 0.9696 p.u. The maximum load carrying factor is also dropped from 1.4024 to 0.7159 . It is noted that, the total capacity of DGs reaches to $3.7150 \mathrm{MW}$ which is nearly the same with the total loads of the system. Compared to results obtained by ACSA [13], SFS [15], SSA [14] and COA [16] methods, power loss earned by the proposed technique is respectively $1.23 \%, 2.61 \%, 2.62 \%$ and $2.61 \%$ lower than that of the above methods but the capacity of DGs pumps to the system is much higher than that of the compared methods. In which, the total capacity of DGs obtained by the proposed method is $0.4605,0.7902,0.7904$ and 0.7902 MW higher that of the ACSA, SFS, SSA and COA methods. The branches' current and nodes' voltage amplitude in Figure 2 show that the benefits gained in improving voltage and reducing overloads after installing DGs are remarkable. For Figure 2 (a) in load carrying factor of branches, and Figure 2 (b) in voltage amplitude of nodes.

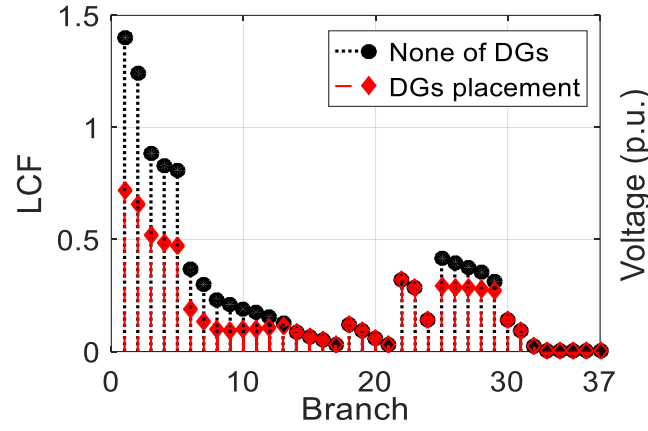

(a)

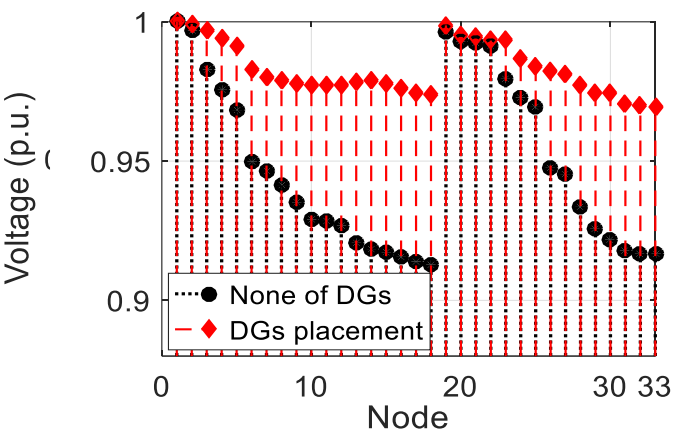

(b)

Figure 2. Branches' current and nodes' voltage of the 33-node network; (a) load carrying factor of branches, (b) voltage amplitude of nodes

For the 69-node system, the optimal DGs location and capacity obtained by the proposed approach is presented in Table 2. After placement three DGs with capacity of $0.5230,1.4242$ and $1.8524 \mathrm{MW}$ at the 17th, 49th and 61th nodes, the power loss has been reduced from $224.8871 \mathrm{~kW}$ to $71.2442 \mathrm{~kW}$. The minimum voltage is increased from the value below the allowable threshold of 0.9092 p.u to 0.9813 p.u. The maximum load carrying factor has also reduced from 1.2413 to 0.6912 . The power loss earned by the proposed technique is $0.53 \%$ and $0.22 \%$ higher than that of the ACSA [13] and TLBO-GWO [17] methods and $0.8 \%$ and $0.82 \%$ lower than compared to SFS [15] and SSA [14] methods. The total capacity of DGs reaches to $3.7996 \mathrm{MW}$ which is respectively $0.817,1.1734,1.1746$ and $1.4936 \mathrm{MW}$ higher than that of the ACSA, SFS, SSA and TLBO-GWO methods. The branches' current and nodes' voltage amplitude presented in Figure 3 shows the robustness of DGs placement for improving the current and voltage profiles. For Figure 3 (a) in load carrying factor of branches, Figure 3 (b) in voltage amplitude of nodes. 
Table 2. Optimal location and capacity of DGs for the 69-node system

\begin{tabular}{lcccccc}
\hline \multicolumn{1}{c}{ Term } & None of DGs & DGs Placement & ACSA [13] & SFS [15] & SSA [14] & TLBO-GWO [17] \\
\hline DGs capacity in & - & $0.5230(17)$ & $0.6022(11)$ & $0.5268(11)$ & $0.527(10)$ & $0.533(18)$ \\
MW (nodes) & & $1.4242(49)$ & $0.3804(18)$ & $0.3804(18)$ & $0.380(17)$ & $1.000(61)$ \\
& & $1.8524(61)$ & $2(61)$ & $1.7190(61)$ & $1.718(60)$ & $0.773(62)$ \\
Total DGs capacity & - & 3.7996 & 2.9826 & 2.6262 & 2.625 & 2.306 \\
$\Delta P(\mathrm{~kW})$ & 224.8871 & 71.2442 & 72.44 & 69.44 & 69.41 & $69.14 \%$ \\
Loss reduction (\%) & - & $68.32 \%$ & $67.79 \%$ & $69.12 \%$ & 6.74 \\
$V_{\min }$ (p.u.) & 0.9092 & 0.9813 & 0.9890 & 0.9790 & 0.9789 \\
$L C F_{\max }$ & 1.2413 & 0.6912 & - & & 0.9791 \\
\hline
\end{tabular}

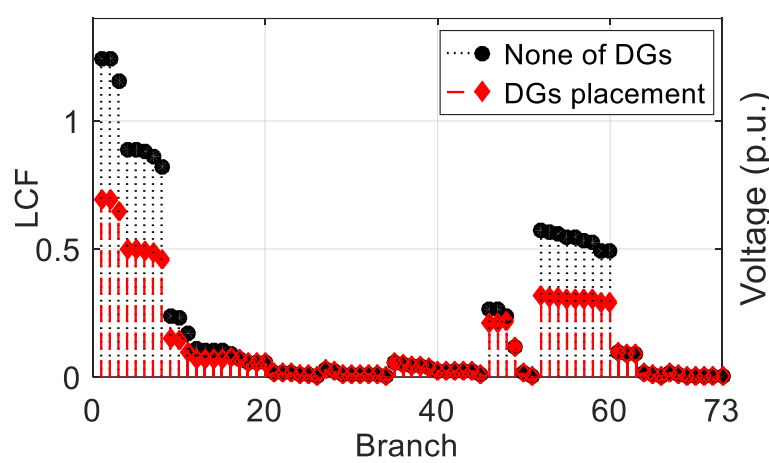

(a)

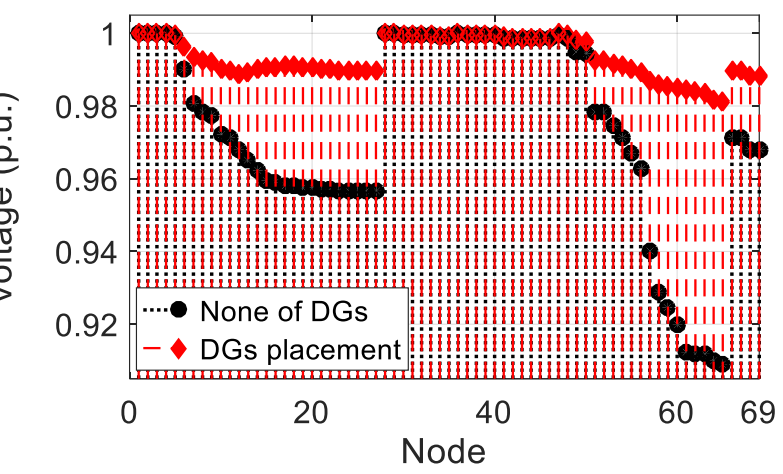

(b)

Figure 3. Branches' current and nodes' voltage of the 69-node network, (a) load carrying factor of branches, (b) voltage amplitude of nodes

\subsection{The performance of CSA}

For the population size and the number of iterations chosen to 30 and 300 for both of the test systems, the obtained results for 50 trials are shown in Table 3. For the first system, the maximum and minimum value of the adaptive function are nearly the same. The standard deviation of the adaptive function (STD_F) in 50 trials is very small. It means that in each execution the convergence value is much closed to the average one. This conclusion is also fully consistent with the results obtained for applying CSA to the second system. These results confirm the reliability of the proposed CSA method to find the optimal solution to the DGs placement problem at each run. The executed times for the 33-node and 69-node networks are 57.5995 and 184.9693 seconds, respectively. The run times for the second system is much higher than that for the first system due to the larger scale of the second system. The average convergence iterations of two test systems are about 268 to 272 iterations. The maximum, average and minimum convergence trends of the proposed CSA for two test system are shown in Figure 4. Figure 4 (a) for 33-nodes system and Figure 4 (b) for 69 -nodes systemIt shows that the average convergence trends are much closed to the minimum ones. This again confirms that CSA tends to find out the optimal solution for the DGs placement problem in each trial.

Table 3. The performance of CSA for the tested systems

\begin{tabular}{lcc}
\hline \multicolumn{1}{c}{ Term } & The 33-node system & The 69-node system \\
\hline Maximum of adaptive function & 0.3848 & 0.32129 \\
Minimum of adaptive function & 0.3787 & 0.3173 \\
Average of adaptive function & 0.3801 & 0.31908 \\
STD_F & 0.0014 & 0.0008 \\
Maximum of convergence iterations & 300 & 300 \\
Minimum of convergence iterations & 176 & 180 \\
Average convergence iterations & 268.8333 & 272.1333 \\
STD of convergence iterations & 28.0628 & 27.1480 \\
Run times (second) & 57.5995 & 184.9693 \\
\hline
\end{tabular}




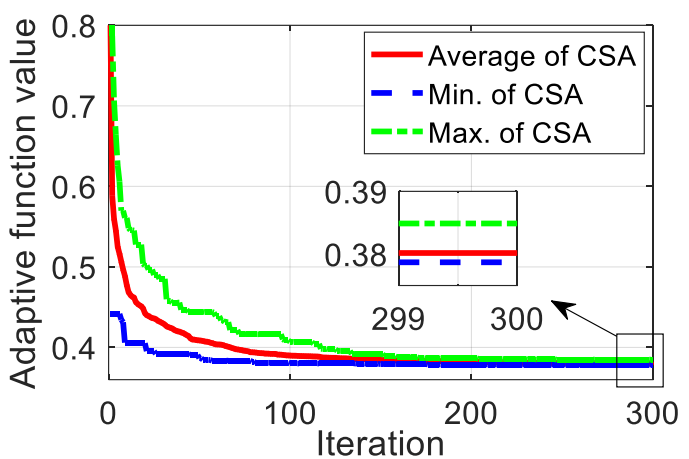

(a)

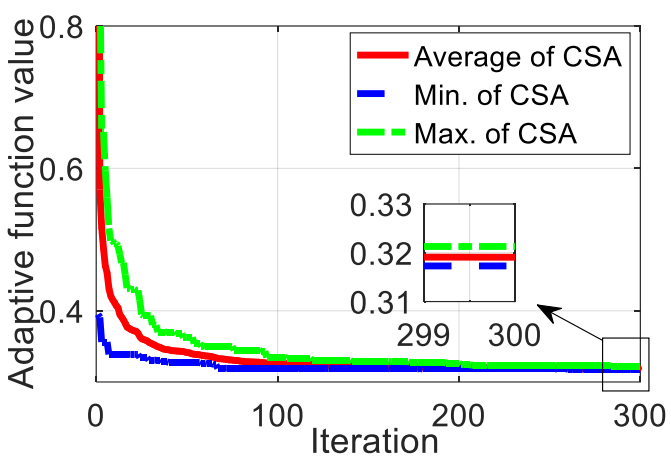

(b)

Figure 4. Convergence curves of CSA for the tested systems, (a) for 33-nodes system, (b) for 69-nodes system

\section{CONCLUSION}

In this paper, the DGs placement problem to maximize the DGs capacity and minimize power loss of distribution system is presented. To search the best location and capacity of DGs, the CSA is adapted to solve the DGs placement problem. The proposed problem and method are simulated on two test systems consisting of the 33-node and 69-node networks. The numerical results have demonstrated that the proposed technique not only reduces power losses but also maximizes the power of DGs pumped into the distribution network. The results also indicate that the proposed CSA method is better performance that some previous methods including ACSA, SFS, SSA, COA and TLBO-GWO for decreasing power loss and increasing DGs capacity. The results obtained in 50 independent trials for two test systems indicate that CSA in one of the reliable methods for the DGs placement problems. Future work may continue to apply the proposed problem and method for practical networks and analysis the impact of maximizing DG capacity to network's indicators in more details.

\section{REFERENCES}

[1] K. Alanne and A. Saari, "Distributed energy generation and sustainable development," Renewable and Sustainable Energy Reviews, vol. 10, no. 6, pp. 539-558, 2006, doi: 10.1016/j.rser.2004.11.004.

[2] W. L. Theo, J. S. Lim, W. S. Ho, H. Hashim, and C. T. Lee, "Review of distributed generation (DG) system planning and optimisation techniques: Comparison of numerical and mathematical modelling methods," Renewable and Sustainable Energy Reviews, vol. 67, pp. 531-573, 2017, doi: 10.1016/j.rser.2016.09.063.

[3] D. Q. Hung, N. Mithulananthan, and R. C. Bansal, "An optimal investment planning framework for multiple distributed generation units in industrial distribution systems," Applied Energy, vol. 124, pp. 62-72, 2014, doi: 10.1016/j.apenergy.2014.03.005.

[4] B. Singh and J. Sharma, "A review on distributed generation planning," Renewable and Sustainable Energy Reviews, vol. 76, no. March, pp. 529-544, 2017, doi: 10.1016/j.rser.2017.03.034.

[5] A A. Keane and M. O'Malley, "Optimal allocation of embedded generation on distribution networks," in IEEE Transactions on Power Systems, vol. 20, no. 3, pp. 1640-1646, Aug. 2005, doi: 10.1109/TPWRS.2005.852115.

[6] Y. M. Atwa, E. F. El-Saadany, M. M. A. Salama and R. Seethapathy, "Optimal Renewable Resources Mix for Distribution System Energy Loss Minimization," in IEEE Transactions on Power Systems, vol. 25, no. 1, pp. 360370, Feb. 2010, doi: 10.1109/TPWRS.2009.2030276.

[7] N. Khalesi, N. Rezaei, and M. R. Haghifam, "DG allocation with application of dynamic programming for loss reduction and reliability improvement," International Journal of Electrical Power and Energy Systems (IJPEDS), vol. 33, no. 2, pp. 288-295, 2011, doi: 10.1016/j.ijepes.2010.08.024.

[8] A. Silvestri, A. Berizzi and S. Buonanno, "Distributed generation planning using genetic algorithms," PowerTech Budapest 99. Abstract Records. (Cat. No.99EX376), 1999, pp. 257-, doi: 10.1109/PTC.1999.826689.

[9] A. Musa and T. J. Tengku Hashim, "Optimal sizing and location of multiple distributed generation for power loss minimization using genetic algorithm," Indonesian Journal of Electrical Engineering and Computer Science (IJEECS), vol. 16, no. 2, pp. 956-963, 2019, doi: 10.11591/ijeecs.v16.i2.pp956-963.

[10] M. H. Moradi and M. Abedini, "A combination of genetic algorithm and particle swarm optimization for optimal DG location and sizing in distribution systems," International Journal of Electrical Power \& Energy Systems, vol. 34, no. 1, pp. 66-74, 2012, doi: 10.1016/j.ijepes.2011.08.023.

[11] O. Olatunde and H. A. Rahman, "Allocation of distributed generation and capacitor banks in distribution system," Indonesian Journal of Electrical Engineering and Computer Science (IJEECS), vol. 13, no. 2, pp. 437-446, 2019, doi: 10.11591/ijeecs.v13.i2.pp437-446.

[12] N. Ghadimi, "Using HBMO Algorithm to Optimal Sizing \& Sitting of Distributed Generation in Power System," 
Bulletin of Electrical Engineering and Informatics (BEEI), vol. 3, no. 1, pp. 1-8, 2014, doi: 10.11591/eei.v3i1.179.

[13] T. T. Nguyen, A. V. Truong, and T. A. Phung, "A novel method based on adaptive cuckoo search for optimal network reconfiguration and distributed generation allocation in distribution network," International Journal of Electrical Power \& Energy Systems, vol. 78, pp. 801-815, 2016, doi: 10.1016/j.ijepes.2015.12.030.

[14] K. S. Sambaiah and T. Jayabarathi, "Optimal reconfiguration and renewable distributed generation allocation in electric distribution systems," International Journal of Ambient Energy, pp. 1-29, 2019, doi: $10.1080 / 01430750.2019 .1583604$.

[15] T. T. Tran, K. H. Truong, and D. N. Vo, "Stochastic fractal search algorithm for reconfiguration of distribution networks with distributed generations," Ain Shams Engineering Journal, vol. 11, no. 2, pp. 389-407, 2020, doi: 10.1016/j.asej.2019.08.015.

[16] T. N. Ton, T. T. Nguyen, V. A. Truong, and T. P. Vu, "Optimal Location and Size of Distributed Generators in an Electric Distribution System Based on a Novel Metaheuristic Algorithm," Engineering, Technology \& Applied Science Research, vol. 10, no. 1, pp. 5325-5329, 2020, doi: 10.48084/etasr.3372.

[17] S. Arabi Nowdeh et al., "Fuzzy multi-objective placement of renewable energy sources in distribution system with objective of loss reduction and reliability improvement using a novel hybrid method," Applied Soft Computing Journal, vol. 77, pp. 761-779, 2019, doi: 10.1016/j.asoc.2019.02.003.

[18] N. Khuan, S. R. A. Rahim, M. H. Hussain, A. Azmi, and S. A. Azmi, "Integration of distributed generation and compensating capacitor in radial distribution system via firefly algorithm," Indonesian Journal of Electrical Engineering and Computer Science (IJEECS), vol. 16, no. 1, pp. 67-73, 2019, doi: 10.11591/ijeecs.v16.i1.pp67-73.

[19] M. Abdelbadea, T. A. Boghdady, and D. K. Ibrahim, "Enhancing active radial distribution networks by optimal sizing and placement of DGs using modified crow search algorithm," Indonesian Journal of Electrical Engineering and Computer Science (IJEECS), vol. 16, no. 3, pp. 1179-1188, 2019, doi: 10.11591/ijeecs.v16.i3.pp1179-1188.

[20] M. N. Morshidi, I. Musirin, S. R. A. Rahim, M. R. Adzman, and M. H. Hussain, "Whale optimization algorithm based technique for distributed generation installation in distribution system," Bulletin of Electrical Engineering and Informatics (BEEI), vol. 7, no. 3, pp. 442-449, 2018, doi: 10.11591/eei.v7i3.1276.

[21] T. T. Nguyen and F. Mohammadi, "Optimal placement of TCSC for congestion management and power loss reduction using multi-objective genetic algorithm," Sustainability (Switzerland), vol. 12, no. 7, pp. 1-15, 2020, doi: $10.3390 / \mathrm{su} 12072813$.

[22] T. T. Nguyen, L. H. Pham, F. Mohammadi, and L. C. Kien, "Optimal scheduling of large-scale wind-hydro-thermal systems with fixed-head short-term model," Applied Sciences (Switzerland), vol. 10, no. 8, 2020, doi: 10.3390/app10082964.

[23] A. H. Shojaei, A. A. Ghadimi, M. R. Miveh, F. Mohammadi, and F. Jurado, "Multi-objective optimal reactive power planning under load demand and wind power generation uncertainties using $\varepsilon$-constraint method," Applied Sciences (Switzerland), vol. 10, no. 8, 2020, doi: 10.3390/app10082859.

[24] X. Yang and Suash Deb, "Cuckoo Search via Lévy flights," 2009 World Congress on Nature \& Biologically Inspired Computing (NaBIC), 2009, pp. 210-214, doi: 10.1109/NABIC.2009.5393690.

[25] I. Fister, X. S. Yang, D. Fister, and I. Fister, "Cuckoo search: A brief literature review," Studies in Computational Intelligence, vol. 516, pp. 49-62, 2014, doi: 10.1007/978-3-319-02141-6_3.

[26] M. E. Baran and F. F. Wu, "Network reconfiguration in distribution systems for loss reduction and load balancing," in IEEE Transactions on Power Delivery, vol. 4, no. 2, pp. 1401-1407, April 1989, doi: 10.1109/61.25627.

[27] H. -. Chiang and R. Jean-Jumeau, "Optimal network reconfigurations in distribution systems. II. Solution algorithms and numerical results," in IEEE Transactions on Power Delivery, vol. 5, no. 3, pp. 1568-1574, July 1990, doi: 10.1109/61.58002. 